Books, videos, CD-ROMs, DVDs and any other relevant items submitted for a review in the $B D J$ should be addressed to: Kate Maynard, Assistant Editor, British Dental Journal, NPG, 4-6 Crinan Street, London N1 9XW

\section{Esthetic rehabilitation in fixed prosthodontics: esthetic analysis - A systematic approach to prosthetic treatment Volume 1}

\author{
M. Fradeani (Ed) \\ UK: Quintessence \\ price $€ 156$, pp352 \\ ISBN 1850971080
}

This is a high-quality textbook with over 300 pages of information about assessing patients who are seeking aesthetic dental treatment. The numerous illustrations, on glossy pages with a black background, are superb in terms of clinical quality and photographic reproduction.

This is the first of two volumes and covers the aesthetic analysis of the face, lips, speech, teeth, and intra-oral soft tissues. Volume 2, which is yet to be published, will cover prosthetic rehabilitation.

There are many examples of high-quality dentistry on patients with healthy soft tissues, excellent oral hygiene, and a desire to have an improved smile. The cases demonstrate the author's and technician's blend of artistic and clinical skills, but the treatments are not conservative. Cases tend towards the full mouth ceramic reconstruction and there is an assumption that all spaces will be closed with a bridge or implant retained restoration.

The post-op views, where shown, are outstanding and the quality of clinical work and laboratory work is unquestionably of a very high standard. Unfortunately not all cases used in the text are shown with postop views and it would also be preferable to see a few cases illustrated at a recall several years later to be able to assess the longerterm aesthetic gain.

The text begins with patient communication and surgery design showing Dr Fradeani's beautiful surgery in Italy. The next section is on facial analysis and, while this cannot be manipulated by dental work alone, it is of interest. Some advice such as looking at the patient from a distance to view the face, and closer to see the mouth and intraoral tissues, seems rather basic. However, the level of detail is generally suited to both the undergraduate and experienced clinician.

Subsequent sections go on to analyse tooth shape and the use of modified transition lines to provide illusion in tooth shape and size. Tooth proportions - the use of the Golden Proportion - dealing with crowding and spacing is also covered in detail, again supported by excellent illustrations and diagrams. The section dealing with mandibular incisors is particularly helpful. Further chapters cover function, aesthetics, occlusion, soft tissues and there is a short section dealing with aesthetics in patients with periodontal disease.

The book is very well presented in a readable style with a balance between text, examples and cases. Checklists provided in each section act as an educational reminder. There is a good example of an entire case assessment at the end of the book and an example of an assessment pro-forma that could be used by the reader.

This is a book to challenge the thinking of the reader, reminding the clinician to spend more time looking outside the patient's mouth and learn what is possible with current materials and techniques. All in all, an outstanding quality production which will inspire and educate at a level of detail suited to almost all members of the clinical team involved with aesthetic dentistry.

B. Millar

Manual of clinical periodontics: a reference manual for diagnosis and treatment

\author{
F.G. Serio, C.E. Hawley \\ USA: Lexi-Comp \\ price $\$ 54.95$, pp 146 \\ ISBN 1930598823
}

This book is presented as a reference manual for dental and dental hygiene students, general dentists and dental hygienists. It is of sturdy construction (spiral-bound with laminated pages) and should withstand the rigours of being transported around in a student's briefcase or backpack. It has 12 chapters, including periodontal diagnosis, anatomy, classification, treatment planning, prevention, non-surgical and surgical treatment. The individual chapters have tabs for easy location.

The book is well illustrated with clinical photographs plus line drawings to explain concepts such as the orientation of incisions for flap surgery. The book is written in a 'Question and Answer' format, which means that preceding each paragraph or small section, a question is posed that is answered in the following text. At first, this seems a good idea certainly it prepares students to answer stock questions that might be fired at them by a teacher. However, at times it can feel very contrived, as if the text was written first and then a question was constructed to fit the text. This results in some strange questions like "What are the consequences of periodontitis that are so worrisome to the periodontist and remedied by osseous surgery?' Although allowing students to learn responses to particular questions, this format may not lead to good, integrated understanding of the topic.

This book is written primarily for US dentists. The appendix on insurance coding has no relevance in the UK, and many of the drugs and oral care products discussed have American trade names which will be unfamiliar to the British reader. No references are cited in the text, but there is an excellent 'Further Reading' section at the end.

Some of the treatment protocols are out of step with modern UK practice. For example, it is suggested that poorlycontrolled diabetics should only receive emergency periodontal treatment and treatment should be covered by systemic antibiotics. It is hard to think of the rationale for this, and this treatment philosophy would not be recommended by any UK dental school. 

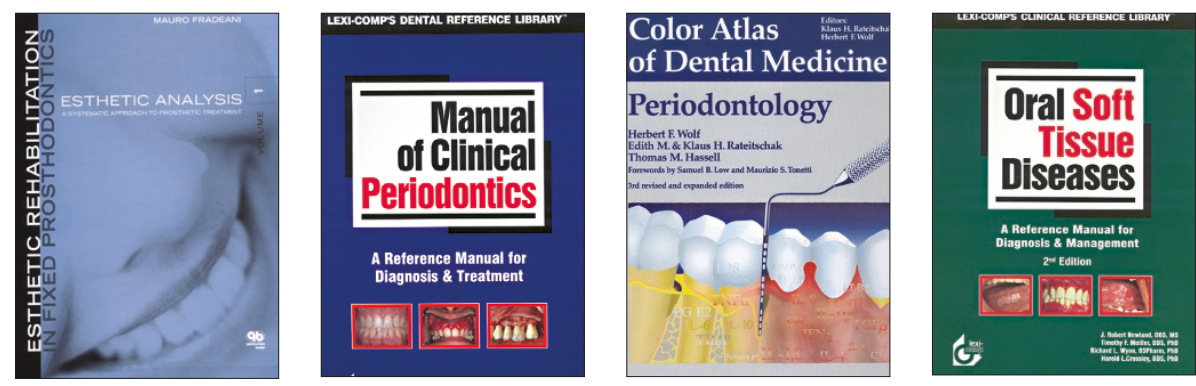

My main concern is that this book is neither adequate for a periodontist (as it does not contain enough information on the detail of periodontal procedures) nor for a general dentist (as it probably contains too much information on periodontal surgery). Perhaps it will be of interest to those general practitioners with an interest in periodontics who wish to have a further reference book for their practice library.

\section{P.M. Preshaw}

\section{Color atlas of dental medicine: Periodontology}

\author{
H.F. Wolf, E.M. Rateitschak, K.H. Rateitschak, T.M. \\ Hassell \\ Germany: Thieme Verlasgruppe \\ price $€ 199.95$, pp531 \\ ISBN 3136750039
}

Colour atlases are often seen as the "coffee table publications' of the medical and dental literature and certainly here is a volume that could comfortably grace the finest coffee tables of the world. This is the third edition of a critically acclaimed book which has been revised and updated since the second edition appeared in 1989. It has also been considerably extended by 200 extra pages to make a total of 530. Indeed, even the description 'colour atlas' greatly undersells this book, which includes sizeable text sections to accompany the wonderful illustrations and clinical photographs.

The book has comprehensive coverage of the field of periodontology. It is divided into 12 main sections detailing aetiology and pathogenesis, classification and types of disease, principles of periodontal treatment, extensive coverage of all treatment modalities in periodontology, and a useful section on adjunctive therapies including orthodontics, prosthodontics and implantology. Within each section specific topics are dealt with, typically on two to three pages with appropriate clinical photos, radiographs, histology and diagrams. The revisions from the second edition are extremely extensive and concepts brought completely up-to-date. Although it would be difficult not to disagree with an occasional statement or aspect in such a comprehensive book as this, in general the line taken on the topics ranges from the traditional (eg modified Widman flap surgery or nonsurgical debridement methods) to the very latest ideas (eg IL-1 genotype testing). All of these are well presented and well balanced. The text is only lightly referenced which some might find disappointing in such a comprehensive book, but this probably helps to maintain the flow of the text. However, interestingly, a very comprehensive list of references (46 pages) are available online from the publisher's website free of charge, in addition to the bibliography within the book

The real beauty of this book is the 1870 figures and illustrations whose quality throughout is truly unsurpassed. This, together with the very high quality of the book production and the superb care that has been taken to assemble the contents make this a truly excellent volume. I cannot imagine any clinician with even a passing interest in periodontology not finding this book an absolute delight, and there is enough information to interest and satisfy the more specialist reader. I would strongly recommend you treat yourself to a copy.

F.J. Hughes

\section{Oral soft tissue diseases: A reference manual for diagnosis and management}

\author{
J.R. Newland, T.F. Meiller, R.L. Wynn, H.L. Crossley \\ USA: Lexi-Comp \\ price $\$ 49.95 / £ 35$, pp138 \\ ISBN 1591950139
}

This slim, A4-sized volume is designed to be a quick, user-friendly reference manual for regular use at the clinic desk rather than sitting on a library bookshelf. It is ring bound with clearly labelled sections and user-friendly dividers to make it easy to access particular topics. Some thought has been put into making the volume sufficiently robust to withstand the rigours of the surgery environment, including the use of heavy duty pages and laminated covers.

The book is well laid out, with one or two pages devoted to the more common oral soft tissue lesions. Each is described in a systematic manner with clearly defined sections devoted to their aetiology, appearance, diagnosis and management. Information is presented in an annotated form with extensive use of bullet points that significantly add to its accessibility. The book is well, but not over illustrated, and at $£ 35$, reasonably priced.

Particularly welcome are the sections devoted to basic pathological terms and diagnostic techniques, the sort of thing we all should know, may well have forgotten and are too embarrassed to ask. Of equal importance is the readily accessible 'special topics' section, which covers a range of issues such as the particular problems, which might be encountered in post radioor chemotherapy patients, a group which the dental clinician is increasingly likely to meet. On a more cautious note, potential readers need to be aware of this book's American origin. While clinical descriptions transcend national boundaries, drug names, and in some instances recommended practices differ between jurisdictions and some of the advice given differs from contemporary British practice. For example, when considering antibacterial prophylaxis in the prevention of endocarditis, the current British recommendations are for $3 \mathrm{~g}$ of oral amoxicillin to be taken one hour prior to the procedure, whereas Oral soft tissue diseases advises a dose of $2 \mathrm{~g}$.

Though this book has a clearly defined role as a valued source of ready information to which a busy clinician particularly a generalist or those working in a discipline outside the oral diagnostic sciences - might refer, it should be remembered that it is no substitute for a basic text, and, as a reference guide, would need to be used with caution, particularly in a British context.

J. Bennett 